\title{
Outcomes of neonates with tracheostomy secondary to bronchopulmonary dysplasia
}

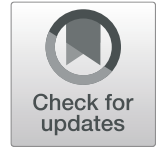

Kirtikumar Upadhyay ${ }^{1,2}$, Dario Antonio Vallarino ${ }^{3}$ and Ajay J. Talati ${ }^{1,4^{*}}$

\begin{abstract}
Background: Bronchopulmonary dysplasia (BPD) is a disease that can affect preterm neonates. Infants with severe BPD may develop pulmonary hypertension (PHN) and may require chronic mechanical ventilation with tracheostomy. The outcomes of these infants have not been studied well. We proposed to review survival and outcomes of infants requiring tracheostomy secondary to severe BPD in our NICU at 24 months.

Methods: We reviewed infants' charts who were diagnosed with BPD that underwent tracheostomy from January 2011 to May 2016 at our children's hospital NICU. Data were recorded from hospital stay as well as from follow up clinics. Institutional review board approval was obtained prior to beginning of study.

Results: Forty-one babies (37 during initial hospitalization and 4 subsequently) requiring tracheostomy were identified from our database. Median gestational age at birth was 26 weeks (25-27 IQR), mean birthweight of $731 \mathrm{~g}$ ( $\pm 245 \mathrm{SD}$ ) and 32\% were small for gestational age (SGA). Median age of tracheostomy placement was 168 days (108-197 IQR), and median PMA 48 wks (40-56 IQR). 26\% of infants requiring tracheostomy also had subglottic stenosis along with BPD. 34 infants (83\%) survived to discharge from NICU. 66\% (27/41) of our patients had a composite outcome of death, ventilator dependency and/or poor neurodevelopmental outcome at 2 years. We found that a higher respiratory severity score at the time of tracheostomy placement and later post-menstrual age at admission to level IV NICU was associated with a worse outcome. Small for gestational age infants were found to have worse outcomes as well. 41\% (13/32) of infants had more than 3 hospital admissions after discharge.

Conclusions: In our cohort about $80 \%$ of infants with severe BPD and tracheostomy survived to discharge with need for prolonged home ventilation in more than half of the survivors. Later postmenstrual age at admission to level 4 NICU was associated with a worse outcome. Our retrospective data may be inadequate to determine the causal relationship between postmenstrual age at admission and outcome. These patients continue to have high morbidity and recurrent hospitalizations.
\end{abstract}

\section{Background}

With advanced technology in health care, survival of extremely low birth infants has been increasing and consequently morbidity associated with prematurity like bronchopulmonary dysplasia (BPD) is on a rise [1-6].

\footnotetext{
*Correspondence: atalati@uthsc.edu

'Division of Neonatal Medicine, Department of Pediatrics, University of Tennessee Health Science Center, 853 Jefferson Avenue, Suite E\#201, Memphis, TN 38103, USA

${ }^{4}$ Department of OB/GYN, University of Tennessee Health Science Center, Memphis, TN, USA

Full list of author information is available at the end of the article
}

Premature infants with BPD are at high risk of mortality, prolonged neonatal intensive care unit (NICU) stay, and significant medical support needs following NICU discharge $[7,8]$. Concurrent with changes in pulmonary management, the incidence of severe BPD has decreased in recent years [9]; however, there remain a subset of infants with BPD whose illness requires chronic, intensive pulmonary management [10]. Currently, no national guidelines or standardized care models are available for this population. In addition, some of these infants

(c) The Author(s). 2020 Open Access This article is licensed under a Creative Commons Attribution 4.0 International License, which permits use, sharing, adaptation, distribution and reproduction in any medium or format, as long as you give appropriate credit to the original author(s) and the source, provide a link to the Creative Commons licence, and indicate if changes were made. The images or other third party material in this article are included in the article's Creative Commons licence, unless indicated otherwise in a credit line to the material. If material is not included in the article's Creative Commons licence and your intended use is not permitted by statutory regulation or exceeds the permitted use, you will need to obtain permission directly from the copyright holder. To view a copy of this licence, visit http://creativecommons.org/licenses/by/4.0/ The Creative Commons Public Domain Dedication waiver (http://creativecommons.org/publicdomain/zero/1.0/) applies to the data made available in this article, unless otherwise stated in a credit line to the data. 
require placement of a tracheostomy to deliver longterm mechanical ventilation [11].

Infants with severe BPD are generally referred to tertiary NICUs at children's hospitals for higher level of care $[12,13]$. The timings of referral to regional NICU [14] and placement of tracheostomy [15] is not uniform across many centers in US [16, 17]. Decisions about whether and when to place a tracheostomy in preterm infants who require prolonged ventilation are challenging due to lack of objective data. Clinicians face significant challenges in counselling these families of infants with severe BPD; which in turn creates more anxiety among parents and subsequently may lead to delay in tracheostomy placement. We wanted to review characteristics and outcomes of infants requiring tracheostomy secondary to severe BPD in our level IV NICU. Our objective was to identify the risk factors associated with poor outcomes of these infants. Such information could help inform clinicians when making decisions with families about the timing of tracheostomy placement and planning for the care of these children throughout early childhood.

\section{Methods}

Our neonatal intensive care unit at Le Bonheur Children Hospital is a tertiary care referral center and an urban, inner city unit. It serves many patients from underserved African American communities who were out born and were transferred to our NICU for multi-specialty involvement with complex needs. Our center is a referral center for west Tennessee and adjacent counties of $\mathrm{Ar}$ kansas and Mississippi. Preterm infants with severe BPD are reviewed and evaluated by multidisciplinary team consisting of neonatology, pediatric pulmonology, pediatric cardiology, pediatric ENT specialist, pediatric anesthetist, nursing teams and physical/occupational therapists. For infants developing severe BPD, our approach include aggressive monitoring (q4weeks echocardiogram) and management of pulmonary hypertension using pulmonary vasodilators such as sildenafil and bosentan, permissive hypercapnia (PCO2 $55-65 \mathrm{~mm}$ of $\mathrm{Hg}$ ) and higher target oxygen saturations (92-98\%). For infants over 36 weeks of corrected gestational age, our ventilation strategies included high tidal volume (8-10 $\mathrm{ml} / \mathrm{kg})$, low vent rate $(20 / \mathrm{min})$ and high inspiratory time (Ti) $>0.5$. We aimed to provide caloric dense feedings with a daily goal of $125-130 \mathrm{kcal} / \mathrm{kg} /$ day and $4.5 \mathrm{~g} / \mathrm{kg} / \mathrm{day}$ of enteral protein to these infants for optimal somatic, linear and lung growth. The timing of placement of tracheostomy in severe BPD infants was dependent on inputs received from interdisciplinary teams. Generally, chronic ventilator dependent status after 44 weeks of corrected gestational age and strong family support/desire for long-term care led to tracheostomy placement.
All our NICU graduates were closely followed up by pulmonologists, developmental pediatricians and psychologists. Developmental assessment was performed as early as 6 months of age and early intervention therapy was offered whenever deemed necessary. The study population derived from the entire population of infants admitted to our NICU from January 2011 to May 2016. Premature infants with severe BPD who underwent tracheostomy placement during this period were identified from our database. We reviewed these infants' charts to confirm the eligibility and data collection. Inclusion criteria were preterm infants less than 34 weeks of gestational age admitted in our level 4 NICU during study period. Infants with complex congenital anomalies, lethal anomalies, trisomy 13 or 18 were excluded.

Data were recorded from hospital stay as well as from follow up clinics. Data were collected for infant and maternal demographics and clinical characteristics. Long term follow-up was assessed at 24 months by noting survival, respiratory status, need for mechanical ventilation and developmental status. Definitions for maternal and infant characteristics were predetermined i.e. gestational age (GA) was determined as the best obstetric estimate or postnatal assessment. Small for GA was defined as BW of $<10$ th percentile using Fenton growth charts. BPD was defined according to the National Institute of Child Health and Development (NICHD) workshop definition [18]; Mild BPD was defined as a need for supplemental oxygen $\left(\mathrm{O}_{2}\right)$ for $\geq 28$ days but not at 36 weeks' postmenstrual age (PMA) or discharge, moderate BPD as $\mathrm{O}_{2}$ for $\geq 28$ days plus treatment with $<30 \% \mathrm{O}_{2}$ at 36 weeks' PMA, and severe BPD as $\mathrm{O}_{2}$ for $\geq 28$ days plus $\geq 30 \% \mathrm{O}_{2}$ and/or positive pressure at 36 weeks' PMA. Respiratory Severity Score (RSS) was calculated as mean airway pressure (MAP) multiplies by FiO2. RSS data were collected on admission to our institution and immediately prior to tracheostomy placement. Pulmonary hypertension (PHN) was diagnosed based on echocardiogram criteria by Pediatric Cardiologists and if it required medical management. After discharge, our pulmonology team followed these infants at home and utilized data such as pulse oximeter, end tidal $\mathrm{CO} 2$ measurement and polysomnography for weaning off the home ventilator. Composite outcome of death or mechanical ventilator dependence and/or poor neurodevelopmental outcome (poor neurodevelopmental outcome defined as MDI and PDI $<70$ by Bayley's scale of Infant development or GMFCS $\geq$ level III) at 24 months of corrected age. The study was approved by the Institutional Review Board at the University of Tennessee Health Science Center. Data were analyzed by descriptive statistics using mean and median. Groups were analyzed using ttest. Categorical variables were compared with chisquare analysis. We used the forward stepwise logistic 
regression analysis for our dataset. This involved starting with no variable in the model, followed by adding a variable whose inclusion gave the most statistically significant outcome and repeating the process until none improved the model to a statistically significant extent. If a nonsignificant variable was found then it was removed from the model.

\section{Results}

Out of 2435 total admissions in NICU from January 2011 to May 2016; 41 infants (1.68\%) required tracheostomy due to prolonged mechanical ventilator need because of BPD. Median gestational age at birth was 26 weeks (23-27 IQR) and mean birthweight was 731( \pm 245) gm. Total $66 \%(27 / 41)$ of infants were born via csection and 73\% (29/41) of infants received antenatal steroids. All infants received surfactant (median 2 doses) and at least one course of postnatal steroids. Almost all infants (98\%) were referred from other level III NICUs. Median peak $\mathrm{FiO} 2$ during the first 30 days was 0.40 (0.35-0.44 IQR), at 36 weeks post-menstrual age (PMA) 0.30 (0.25-0.4 IQR), and at time of tracheostomy placement 0.35 (0.32-0.45 IQR). PHN was diagnosed in 61\% $(25 / 41)$ of our cases which was associated with $36 \%$ (9/ 25) mortality. $88 \%(22 / 25)$ of infants with pulmonary hypertension received sildenafil. Median age of tracheostomy placement was 168 days (108-197 IQR), and median PMA 48 wks (40-56 IQR). 26\% of infants requiring tracheostomy also had subglottic stenosis along with
BPD. G-tube was placed on all surviving infants- $83 \%$ $(34 / 41)$, while $17 \%$ (7/41) died prior to discharge from NICU and $66 \%(27 / 41)$ of our patients had a composite outcome of death, home mechanical ventilation need and/or poor neurodevelopmental outcome by 2 years of corrected age. As shown in Table 1, we found that infants who were transferred to our NICU at a later postmenstrual age had worse outcome compared to the infants who were transferred earlier after birth. (35 vs. 39 wks, $p$-value 0.03). Small for gestational age infants had poor outcomes as well. Higher RSS prior to tracheostomy placement was associated with poor outcomes. The other characteristics of infants with good and poor outcomes have been described in Table 1. 41\% (14/34) of infants had more than 3 hospital admissions after discharge from NICU.

Furthermore, forward stepwise logistic regression data suggest that poor outcomes at 2 years of corrected age in infants with severe BPD and tracheostomy was associated with SGA status at birth, pulmonary hypertension, RSS at the time of tracheostomy placement and PMA at the time of admission to our institution (Table 2). The surviving infants were followed for 2 years of corrected age. More than half of infants in our cohort were found to be ventilator dependent at 2 years of age and of which $61 \%$ had poor neurodevelopmental outcome at 24 months of corrected age (Table 3).

Table 1 The characteristics of infants with BPD who received tracheostomy

\begin{tabular}{|c|c|c|c|}
\hline Variable & $\begin{array}{l}\text { Poor Outcome } \\
(n=27)\end{array}$ & $\begin{array}{l}\text { Good outcome } \\
(n=14)\end{array}$ & $P$ value \\
\hline $\begin{array}{l}\text { Gestational Age (wks) } \\
\text { Mean, SD }\end{array}$ & $26.5 \pm 1.8$ & $26 \pm 2.3$ & 0.44 \\
\hline $\begin{array}{l}\text { Post-conceptional age at admission (wks) } \\
\text { Mean, SD }\end{array}$ & $39.1 \pm 7.5$ & $34.6 \pm 5.4^{*}$ & 0.05 \\
\hline Male (\%) & 19/27 (70\%) & $9 / 14(64 \%)$ & 0.69 \\
\hline $\begin{array}{l}\text { Birthweight }(\mathrm{kg}) \\
\text { Mean, SD }\end{array}$ & $0.68 \pm 0.17$ & $0.83 \pm 0.34$ & 0.06 \\
\hline Small for gestational age & $12 / 27$ & $2 / 14$ & 0.11 \\
\hline $\begin{array}{l}\text { FiO2 at } 36 \text { wks CGA } \\
\text { Mean, SD }\end{array}$ & $0.40 \pm 0.17$ & $0.30 \pm 0.08^{*}$ & 0.04 \\
\hline $\begin{array}{l}\text { RSS prior to tracheostomy } \\
\text { Mean, SD }\end{array}$ & $4.8 \pm 1.8$ & $3.6 \pm 1.4^{*}$ & 0.03 \\
\hline $\begin{array}{l}\text { Post-conceptional age at tracheostomy (wks) } \\
\text { Mean, SD }\end{array}$ & $50.9 \pm 8.9$ & $49.6 \pm 14.6$ & 0.72 \\
\hline Pulmonary Hypertension (\%) & 19/27 (70\%) & $6 / 14(43 \%)^{*}$ & 0.049 \\
\hline Sepsis & $14 / 27(51 \%)$ & $6 / 14(43 \%)$ & 0.58 \\
\hline Mode of delivery & $18 / 27(66 \%)$ & $9 / 14(64 \%)$ & 0.87 \\
\hline Postnatal steroids & $27 / 27(100 \%)$ & $14 / 14(100 \%)$ & 0.65 \\
\hline Antenatal steroids & $18 / 27(66 \%)$ & $11 / 14(78 \%)^{*}$ & 0.42 \\
\hline
\end{tabular}

(* $p$ value $\leq .05)$ 
Table 2 Forward step logistic regression analysis for risk factors associated with poor outcomes in infants with severe BPD requiring tracheostomy

\begin{tabular}{lll}
\hline Infant characteristics & Odds Ratio Estimate & 95\% Wald Confidence Interval \\
\cline { 2 - 3 } & Point estimate & $1.921-2.699$ \\
\hline Post conceptional age at admission (continuous) & $2.251^{*}$ & $1.635-3.438$ \\
Higher RSS prior to tracheostomy placement & $1.985^{*}$ & $1.123-11.391$ \\
Small for gestational age & $3.577^{*}$ & $0.570-2.503$ \\
Antenatal steroids & 1.195 & $1.683-9.373$ \\
Pulmonary hypertension & $3.972^{*}$ & \\
\hline
\end{tabular}

${ }^{*} p$ value $<0.05$

\section{Discussion}

Parents experience overwhelming anxiety and stress when discussing tracheostomy placement and they often worry about "how long my child will be dependent on mechanical ventilator for his/her breathing?" [19].In a single center cohort of infants with severe BPD and tracheostomy, our data demonstrated that median post menstrual age for placement of tracheostomy was 48 weeks. This is consistent with other reports in the literature [11]. The timing of decannulation and independence from ventilator is an extremely important milestone for infants with severe BPD [20]. Our study showed that $2 / 3 \mathrm{rd}$ of infants requiring tracheostomy were vent dependent even at 2 years of age. Our data showed that higher respiratory severity score at the time of tracheostomy placement and later gestational age was associated with poor outcomes at 24 months of corrected gestational age. These are our data based on institutional practice, but there is no national consensus on timing of tracheostomy placement for BPD. We want to caution the readers that these findings may not be applicable to all institutions.

This study also points that small for gestational age, need for higher supplemental oxygen at 36 weeks of corrected gestational age and presence of pulmonary hypertension are predictors of poor outcomes in our cohort at 2 years of age. Studies done by Mourani et al [21, 22], have shown that pulmonary hypertension may significantly worsen the outcome in BPD infants. Pulmonary hypertension was diagnosed based on echocardiographic findings. Cardiac catheterization to measure pulmonary pressures is not routinely performed in our unit and

Table 3 Outcomes at 24 months in surviving infants. Data are not mutually exclusive

\begin{tabular}{ll}
\hline Outcomes at 24 months (corrected age) & $n=34$ \\
\hline Death after discharge from NICU & $2(6 \%)$ \\
Ventilator dependent & $18(53 \%)$ \\
MDI and PDI $<70$ or GMFCS $\geq$ level III & $11(32 \%)$ \\
Hospital readmission (more than 3 times) & $14(41 \%)$ \\
\hline
\end{tabular}

MDI mental development index, PDI psychomotor development index, GMFCS gross motor function classification system other NICUs. This may be one of the limiting factors of our study as some cases of pulmonary hypertension might be missed with the use of echocardiography alone [23]. Nevertheless, it remains the best non-invasive screening tool to assess pulmonary hypertension in infants with severe BPD. Even though the accuracy of the echocardiogram may be limited regarding the ability to find a measurable and reproducible tricuspid regurgitant jet velocity to estimate right ventricular systolic pressure, we have an institutional, evidence-based guidelines [24], formed by a multi-specialty committee including neonatology, cardiology and pulmonology teams to diagnose pulmonary hypertension based on echocardiogram criteria in BPD infants. In our study, we found that these above-mentioned risk factors were associated with vent dependency and/or death based on forward step logistic regression analysis. However; only the "sickest" infants with pulmonary diseases were referred to our institution for multi-specialty consultations and were included in this study. We could not include all other infants with less severe $\mathrm{BPD}$ in our regression model to make our analysis more robust.

Our institutional data also demonstrates that later gestational age at referral is associated with worse outcomes. Association between the time of referral and poor outcome has not been reported elsewhere. Due to small data set, we are not able to prove any causality. The availability of multi-specialty care at tertiary NICU helps with consistency of care but the evidence for improving outcome secondary to that is lacking. Also, many infants that need tertiary care are already burdened with complex disease problems and delay in transfer to tertiary care NICUs may be secondary to their prolonged sickness or instability of condition precluding early transfer.

Our children's hospital receives patients from diverse NICUs across 150 mile $^{2}$ area located in 4 different states. The antenatal care, availability of resources, ventilatory strategies, approach to delivery room care, PDA management, nutritional management, level of clinical expertise have been very different among these NICUs which complicated the evaluation and comparison of these 
infants at admission. NICHD consensus statement for management of BPD infants recommends involvement of interdisciplinary team at 36 weeks of gestation, which was not readily available at many of our referring hospitals. Uniform guidelines for ventilatory, nutrition and infection management in collaboration with multispecialty teams and interdisciplinary approach may contribute towards improved outcomes [17, 25, 26]. This finding is interesting and may need to be studied further to address this specific question.

RSS at admission was not comparable for these infants due to significant difference of clinical management among referring hospitals. RSS data at the time of tracheostomy placement may suggest severe lung disease in infants, which was also predictive of poor outcome at 24 months of age.

Our long term follow up data at 2 years of age showed that; $66 \%$ of infants in our cohort died or were vent dependent. Around 33\% of surviving infants had poor neurodevelopmental outcome based on BSID III and GMFCS criteria. The mobility, gross motor and some aspects of neurodevelopmental milestones are dependent on infant's ventilator dependent status. This may be one of the reasons for such a high number of infants with poor neurodevelopment outcomes in our cohort.

The primary limitation of this study is that the analysis is retrospective in nature, is from a single center and there is no comparison group, hence these data may not be generalizable. Our study is also missing prenatal information to identify the risk factors that may be associated with poor outcomes. Our objective was to identify the risk factors associated with poor outcomes in severe BPD infants; however, as a referral center NICU and due to retrospective nature of our study; we could not collect all prenatal, intrapartum and postnatal characteristics of these infants. This may limit our ability to identify all potential risk factors associated with poor outcomes in severe BPD infants. On the other hand, our study represents a largest data till now from a single center in infants with severe BPD requiring tracheostomy.

\section{Conclusions}

In summary, our data identified some clinical risk factors associated with poor outcomes at 2 years of age in single center cohort of infants with severe BPD. These results can be used to assist in counseling parents/families of infants with severe pulmonary disease. Furthermore, clinicians and families need to be diligent towards potential risk for poor neurodevelopmental outcomes of these infants. Modification of these risk factors may be helpful in decreasing severe respiratory and neurodevelopmental outcomes or death. Our data does not identify optimal timing of tracheostomy placement in these babies. Future research directed at understanding this gap will assist referral NICUs in the provision of potentially improved clinical practices to optimize these infants' health outcomes.

\section{Abbreviations}

BPD: Bronchopulmonary dysplasia; BSID: Bayley's Scales of Infant Development; GA: Gestational age; GMFCS: Gross motor function classification scale; IQR: Interquartile range; NICHD: National Institute of Child Health and Development; NICU: Neonatal intensive care unit; PDA: Patent Ductus Arteriosus; PHN: Pulmonary Hypertension; PMA: Postmenstrual age; RSS: Respiratory severity score

\section{Acknowledgements}

Not applicable.

\section{Authors' contributions}

AT, KU and DV all contributed equally to study design, data analyses and manuscript writing. AT and KU were responsible for review and editing of final manuscript. All authors have read and approved the manuscript.

\section{Funding}

No external funding was received for this study.

\section{Availability of data and materials}

The datasets used and/or analysed during the current study are available from the corresponding author on reasonable request.

\section{Ethics approval and consent to participate}

The University of Tennessee Health Science Center Institutional Review Board approved the study and consent was waived because of the retrospective chart review study (IRB \#16-04653-XP).

Consent for publication

Not applicable.

\section{Competing interests}

There are no competing interests to disclose by any authors.

\section{Author details}

'Division of Neonatal Medicine, Department of Pediatrics, University of Tennessee Health Science Center, 853 Jefferson Avenue, Suite E\#201, Memphis, TN 38103, USA. ²Department of Pediatrics, University of Washington, Seattle, USA. ${ }^{3}$ Division of Neonatology, Kids Medical Services, Miami, FL, USA. ${ }^{4}$ Department of OB/GYN, University of Tennessee Health Science Center, Memphis, TN, USA.

Received: 12 July 2020 Accepted: 27 August 2020

Published online: 01 September 2020

\section{References}

1. Stoll BJ, Hansen NI, Bell EF, Walsh MC, Carlo WA, Shankaran S, et al. Trends in care practices, morbidity, and mortality of extremely preterm neonates, 1993-2012. JAMA. 2015;314:1039-51.

2. Bancalari $E$, Claure N, Sosenko IR. Bronchopulmonary dysplasia: changes in pathogenesis, epidemiology and definition. Semin Neonatol. 2003:8:63-71.

3. Latini G, Felice C, Giannuzzi R, Del Vecchio A. Survival rate and prevalence of bronchopulmonary dysplasia in extremely low birth weight infants. Early Hum Dev. 2013;89:69-73.

4. Costeloe KL, Hennessy EM, Haider S, Stacey F, Marlow N, Draper ES. Short term outcomes after extreme preterm birth in England: comparison of two birth cohorts in 1995 and 2006 (the EPICure studies). BMJ. 2012;345:e7976.

5. Wang C, Kou Y, Shah G, Mitchell R, Johnson R. Tracheostomy in extremely preterm neonates in the United States: a cross sectional analysis. Laryngoscope. 2019;00:1-7.

6. Hintz SR, Poole WK, Wright LL, Fanaroff AA, Kendrick DE, Laptook AR, et al. For NICHD neonatal research network. Changes in mortality and morbidities among infants born at less than 25 weeks during the post-surfactant era. Arch Dis Child Fetal Neonatal Ed. 2005;90(2):F128-33.

7. Jobe AH. The new bronchopulmonary dysplasia. Curr Opin Pediatr. 2011;23: 167-72. 
8. Ehrenkranz RA, Walsh MC, Vohr BR, Jobe AH, Wright LL, Fanaroff A, et al. Validation of the National Institutes of Health consensus definition of bronchopulmonary dysplasia. Pediatrics. 2005;116:1353-60.

9. Van Marter $\sqcup$. Epidemiology of bronchopulmonary dysplasia. Semin Fetal Neonatal Med. 2009;14:358-66.

10. Natarajan G, Pappas A, Shankaran S, Kendrick DE, Das A, Higgins RD, et al. Outcomes of extremely low birth weight infants with bronchopulmonary dysplasia: impact of the physiologic definition. Early Hum Dev. 2012;88:50915.

11. Mandy G, Malkar M, Welty SE, Brown R, Shepherd E, Gardner W, et al. Tracheostomy placement in infants with bronchopulmonary dysplasia: safety and outcomes. Pediatr Pulmonol. 2013;48:245-9.

12. American Academy of Pediatrics. Committee of Fetus and Newborn. Levels of Neonatal care. Pediatrics. 2012;130:587-97.

13. Helenius K, Gissler M, Lehtonen L. Trends in centralization of very preterm deliveries and neonatal survival in Finland in 1987-2017. Transl Pediatr. 2019; 8(3):227-32.

14. Lasswell SM, Barfield WD, Rochat RW, Blackmon L. Perinatal regionalization for very low-birth-weight and very preterm infants: a meta-analysis. JAMA. 2010;304:992-1000.

15. Abman S, Collaco J, Shepherd E, Keszler M, Welty S, et al. Interdisciplinary Care of Children with severe Bronchopulmonary dysplasia. J Pediatr. 2017; 181:12-28.

16. Padula MA, Grover TR, Brozanski B, Zaniletti I, Nelin LD, Asselin JM, et al. Therapeutic interventions and short-term outcomes for infants with severe bronchopulmonary dysplasia born at $<32$ weeks' gestation. J Perinatol. 2013:33:877-81.

17. Guaman MC, Gien J, Baker CD, Zhang H, Austin ED, Collaco JM. Point prevalence, clinical characteristics, and treatment variation for infants with severe bronchopulmonary dysplasia. Am J Perinatol. 2015;32:960-7.

18. Jobe AH, Bancalari E. Bronchopulmonary dysplasia. Am J Respir Crit Care Med. 2001;163(7):1723-9.

19. Joseph RA, Goodfellow LM, Simko LM. Parental quality of life: caring for an infant or toddler with a tracheostomy at home. Neonatal Network. 2014; 33(2):86-94.

20. Pereira KD, Smith SL, Henry M. Failed extubation in the neonatal intensive care unit. Int J Pediatr Otorhinolaryngol. 2007;71(11):1763-6.

21. Mourani PM, Sontag MK, Younoszai A, et al. Early pulmonary vascular disease in preterm infants at risk for bronchopulmonary dysplasia. Am J Respir Crit Care Med. 2015;191(1):87-95.

22. Mourani PM, Abman SH. Pulmonary hypertension and vascular abnormalities in bronchopulmonary dysplasia. Clin Perinatol. 2015;42:83955.

23. Mourani PM, Sontag MK, Younoszai A, IVy DD, Abman SH. Clinical utility of echocardiography for the diagnosis and management of pulmonary vascular disease in young children with chronic lung disease. Pediatrics. 2008;121:317-25

24. Collaco JM, Romer LH, Stuart BD, Coulson JD, Everett AD, Lawson EE, et al. Frontiers in pulmonary hypertension in infants and children with bronchopulmonary dysplasia. Pediatr Pulmonol. 2012:47:1042-53.

25. Gien J, Kinsella J, Thrasher J, Grenolds A, Abman SH, Baker CD. Retrospective Analysis of an Interdisciplinary Ventilator Care Program Intervention on Survival of Infants with Ventilator-Dependent Bronchopulmonary Dysplasia. Am J Perinatol. 2017;34(2):155-63.

26. Birenbaum HJ, Dentry A, Cirelli J, Helou S, Pane MA, Starr K, et al. Reduction in the incidence of chronic lung disease in very low birth weight infants: results of a quality improvement process in a tertiary level neonatal intensive care unit. Pediatrics. 2009;123(1):44-50

\section{Publisher's Note}

Springer Nature remains neutral with regard to jurisdictional claims in published maps and institutional affiliations.

Ready to submit your research? Choose BMC and benefit from:

- fast, convenient online submission

- thorough peer review by experienced researchers in your field

- rapid publication on acceptance

- support for research data, including large and complex data types

- gold Open Access which fosters wider collaboration and increased citations

- maximum visibility for your research: over $100 \mathrm{M}$ website views per year

At $\mathrm{BMC}$, research is always in progress.

Learn more biomedcentral.com/submissions 